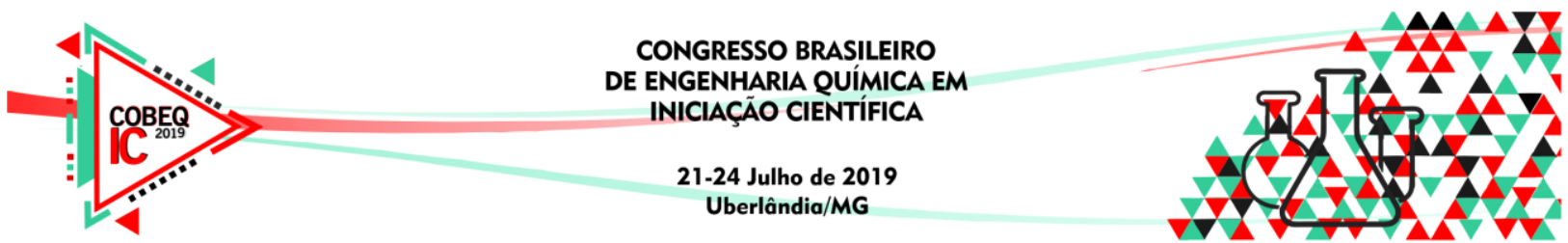

\title{
PRODUÇÃO DE CERVEJA ARTESANAL COM ADIÇÃO DE ÁCIDO ASCÓRBICO A PARTIR DE FRUTO AMAZÔNICO
}

\author{
C. E. M. PIMENTEL ${ }^{1}$, I. L. SANTIAGO ${ }^{1}$, S. K. M. S. OLIVEIRA ${ }^{1}$ e R. L. SERUDO ${ }^{2}$ \\ ${ }^{1}$ Discente de Engenharia Química da Universidade do Estado do Amazonas, Escola Superior \\ de Tecnologia \\ ${ }^{2}$ Docente de Engenharia Química da Universidade do Estado do Amazonas, Escola Superior \\ de Tecnologia \\ E-mail para contato: cemp.eng16@uea.edu.br
}

\begin{abstract}
RESUMO - Na produção de cerveja artesanal é comum o uso de frutas como adjunto. Atualmente, a fruta com maior teor de vitamina $\mathrm{C}$ no Brasil é o camucamu que chega a ter 2,4 a $3,0 \mathrm{~g} / 100 \mathrm{~g}$ de polpa. O uso do camu-camu neste trabalho é justificado por ser considerado um Tesouro Amazônico, com alto potencial socioeconômico e nutricional para a região, porém pouco explorado. Com objetivo de agregar vitamina $\mathrm{C}$ à cerveja, adicionou-se $200 \mathrm{~g}$ do fruto de camu-camu no processo cervejeiro, nos 5 minutos finais de fervura. Para quantificar o teor de ácido ascórbico na cerveja artesanal, fez-se análise em HPLC com detector PDA (fase móvel: ácido sulfúrico 0,01\%; fase estacionária: C18) com as seguintes amostras (em triplicata): branco (contendo somente a fase móvel, ácido sulfúrico 4,5\%), solução de ácido ascórbico em diferentes concentrações $(0.5,1,1.5,3$ e $5 \mathrm{mg} / 100 \mathrm{~mL}$ ), cerveja piloto (com camu-camu), cerveja controle (sem camu-camu), cerveja comercial do estilo Witbier (mesmo estilo da cerveja piloto) e o extrato da fruta. Constatou-se que nas cervejas controle e comercial não havia ácido ascórbico. Porém na cerveja artesanal com adjunto de camu-camu encontrou-se uma concentração de $15,8 \mathrm{mg} / 100 \mathrm{~mL}$. Sabendo que a quantidade diária mínima necessária de vitamina $\mathrm{C}$ para o homem é de $90 \mathrm{mg}$, conclui-se que $600 \mathrm{~mL}$ da cerveja produzida seria o suficiente para gerar benefícios ao corpo humano.
\end{abstract}

\section{INTRODUÇÃO}

Cerveja é definida por Sakamaka (2016) como uma bebida alcoólica, produzida a partir de cevada, água, lúpulo e levedura. Cada vez mais novos tipos de cerveja são disponibilizados no mercado como, por exemplo, a utilização de frutas como adjunto que garantem uma doçura residual, aroma e sabor cítrico e característico. Um estilo muito conhecido por seu característico sabor frutado é o Witbier. De acordo com Morado (2009), as cervejas Witbier são cervejas artesanais originalmente belgas, feitas de trigo com adição de especiarias (coentro e cascas de laranja).

Segundo Zamudio (2007), Camu-camu (Myciaria dubia H.B.K. McVaugh) é uma fruta típica da região Amazônica que tem elevado potencial como alimento funcional por apresentar elevada capacidade antioxidante, devido ao seu elevado teor ascórbico. Os frutos 


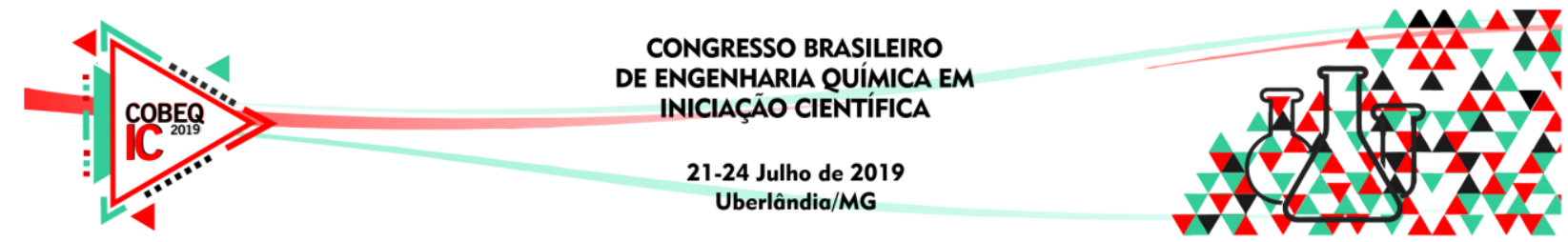

de camu-camu produzidos em Manaus, no Instituto Nacional de Pesquisa da Amazônia (INPA), possuem teores de vitamina $\mathrm{C}$ que variam entre 2,4 a 3,0 g/100g de polpa, cujo valor é superior à de acerola $(1,79 \mathrm{~g} / 100 \mathrm{~g}$ de polpa) até então considerada a fruta mais rica nessa vitamina.

O camu-camu é considerado um Tesouro Amazônico, de acordo com Zamudio (2007), por ser uma cultura com alto potencial socioeconômico e nutricional para a região, pois, além de melhorar a dieta da população, também contribui para o aumento da renda das comunidades nativas. É uma excelente alternativa econômica e ecológica por não envolver altos custos de produção no cultivo e pelos frutos possuírem sementes necessárias para novas produções da população, podendo tornar-se uma fonte de renda para os agricultores da região Amazônica, gerando ocupação permanente ao ribeirinho, pescador e agricultor sazonal.

O estudo realizado tem como objetivo inserir vitamina $\mathrm{C}$ (ácido ascórbico) na cerveja artesanal através da utilização de camu-camu como adjunto, com o intuito da bebida gerar benefícios à saúde humana. A partir das análises feitas, buscou-se quantificar a concentração de ácido ascórbico na cerveja produzida e comparar com dados da literatura, além de avaliar se supria as necessidades nutricionais para o ser humano.

\section{METODOLOGIA}

\subsection{Preparo da Cerveja}

Escolheu-se uma receita do estilo Witbier para a fabricação de $20 \mathrm{~L}$ de cerveja. Utilizou-se $2 \mathrm{~kg}$ de malte de cevada, $2 \mathrm{~kg}$ de malte de trigo claro, $100 \mathrm{~g}$ de malte Munich, $400 \mathrm{~g}$ de aveia de flocos finos, $36 \mathrm{~g}$ de lúpulo Mittelfruh, $20 \mathrm{~g}$ de coentro macerado. E $200 \mathrm{~g}$ da fruta (amassada com auxílio de almofariz e pistilo). Separou-se aproximadamente $5 \mathrm{~L}$ do mosto antes da adição de camu-camu, para controle. No restante, adicionou-se a fruta nos últimos 5 minutos do processo de fervura.

\subsection{Preparo do Extrato para análise}

Para o preparo do extrato, pesou-se $25 \mathrm{~g}$ da fruta e amassou-se com auxílio de almofariz de quartzo e pistilo. Posteriormente, adicionou-se $25 \mathrm{~mL}$ de uma solução de ácido fosfórico 4,5\%. Deixou-se em agitação magnética por 30 min e em descanso para decantação por mais $10 \mathrm{~min}$. Utilizou-se filtro de café de pano para que o extrato ficasse o mais líquido possível.

\subsection{Análise em HPLC}

Utilizou-se o equipamento de HPLC (High Perfomance Liquid Chromatography) da marca Shimadzu com detector de arranjo de diodos (PDA) trabalhando com comprimento de onda de $254 \mathrm{~nm}$. As amostras foram introduzidas na coluna através de um injetor manual equipado com um loop de amostras $(20 \mu \mathrm{L})$. A vazão foi fixada a $1,0 \mathrm{~mL} / \mathrm{min}$ à temperatura ambiente. A fase estacionária utilizada foi a C18 e a fase móvel foi uma solução de ácido sulfúrico $0,01 \%$. Foram introduzidas 30 frascos no HPLC, pois o procedimento foi feito em 


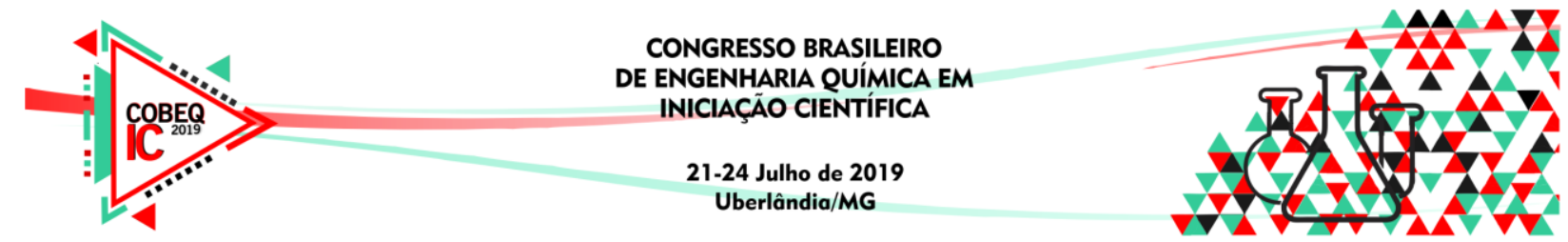

triplicata com as seguintes amostras: branco (somente a fase móvel, ácido sulfúrico 4,5\%), solução de ácido ascórbico em diferentes concentrações $(0.5,1,1.5,3$ e $5 \mathrm{mg} / 100 \mathrm{~mL})$, cerveja piloto (com camu-camu), cerveja controle (sem camu-camu), cerveja comercial do estilo Witbier (mesmo estilo da cerveja piloto) e o extrato da fruta. Todas as amostras foram previamente filtradas com filtro de seringa e, exceto os padrões de ácido ascórbico, foram diluídas em 10 vezes.

\section{RESULTADOS E DISCUSSÃO}

Com a cerveja artesanal pronta (Figura 4), calculou-se as estatísticas vitais para verificar se correspondiam com a literatura de uma Witbier. Os dados estão dispostos na Tabela 1 e, de acordo com Beer Judge Certification Program (BJCP), estão de acordo com os padrões do estilo Witbier.

Figura 4 - Cerveja Artesanal com adjunto de camu-camu.

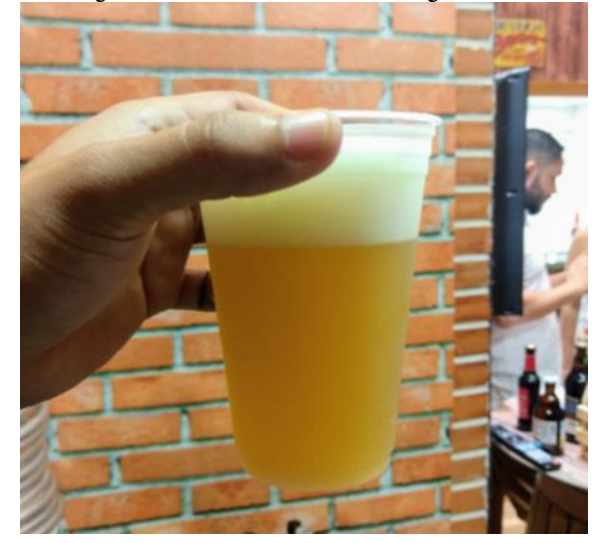

Tabela 1: Características Gerais da Cerveja Produzida

\begin{tabular}{|c|c|c|}
\hline Característica & Valor Obtido & Valor BJCP \\
\hline OG & 1,050 & $1,044-1,052$ \\
\hline FG & 1,012 & $1,008-1,012$ \\
\hline IBU & $16,22 \mathrm{IBU}$ & $8-20$ \\
\hline ABV & $4,98 \%$ & $4,5-5,5 \%$ \\
\hline
\end{tabular}

Posteriormente, analisou-se as amostras através do HPLC-PDA e obteve-se vários cromatogramas apresentando o tempo de retenção em função da absorbância e quatro deles estão dispostos abaixo, da Figura 5 até a Figura 8.

Figura 5 - Cromatograma Cerveja Artesanal Comercial estilo Witbier. 


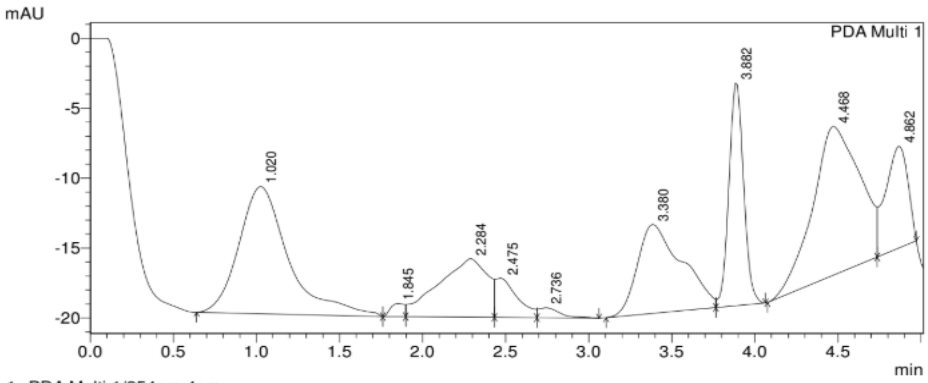

Figura 6 - Cromatograma Cerveja Artesanal sem camu-camu.

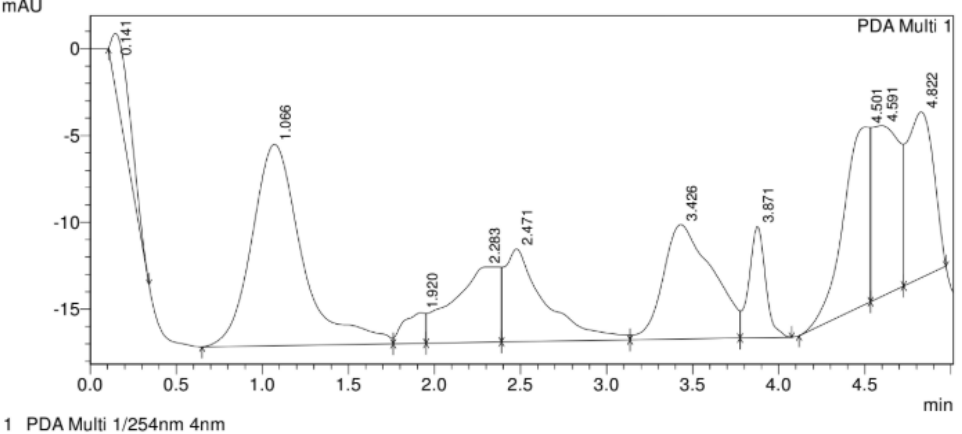

Figura 7 - Cromatograma do Extrato do Camu-Camu.

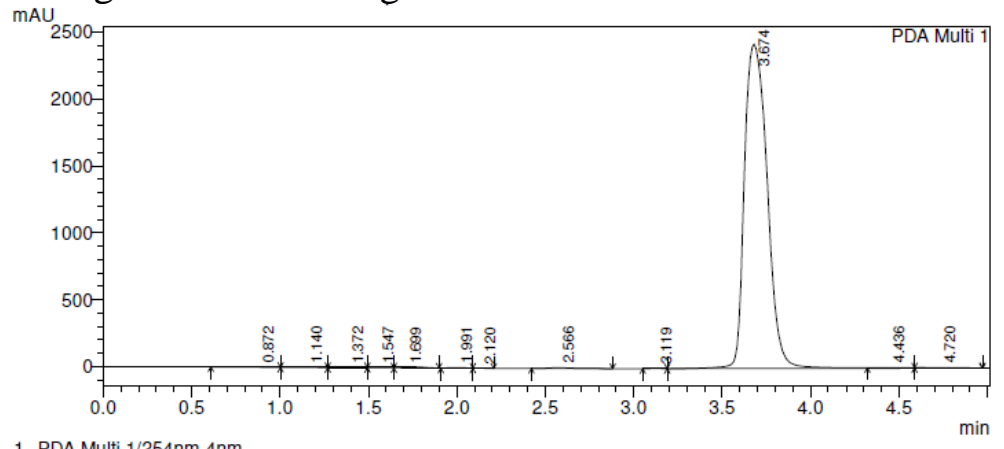

1. PDA Multi $1 / 254 \mathrm{~nm} 4 \mathrm{~nm}$

Figura 8 - Cromatograma da Cerveja que continha Camu-Camu.

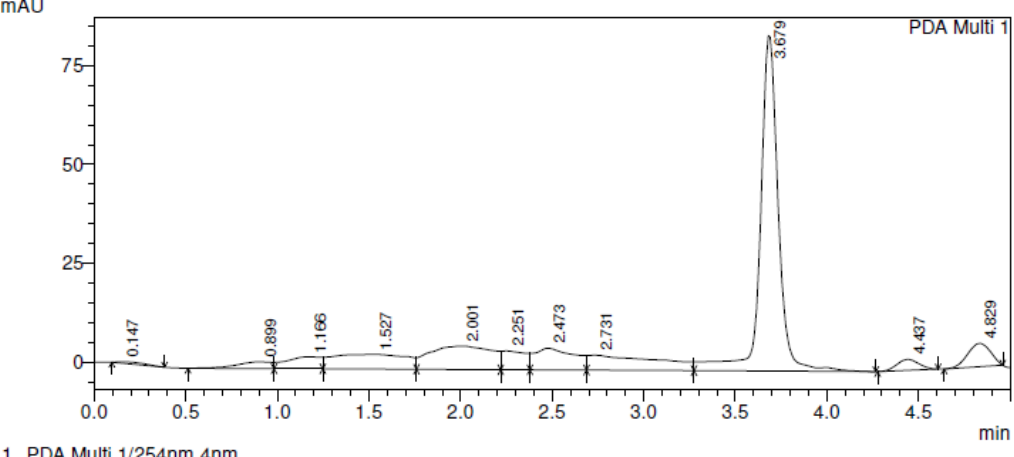

Nota-se que na Figura 5 e 6 não se observa o pico característico de ácido ascórbico no tempo de retenção padrão de 3,565 minutos, de acordo com Rosa (2007). Já na Figura 7 e 8, 


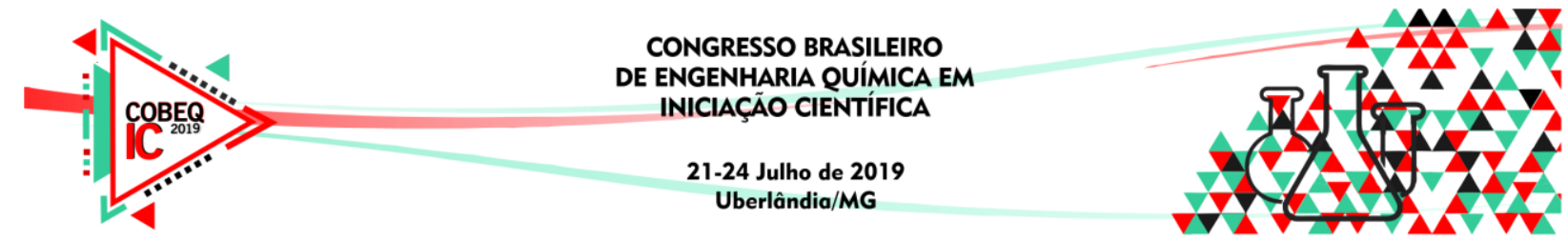

onde há presença do camu-camu, os cromatogramas do extrato e da cerveja com adjunto apresentaram picos nos tempos de retenção 3,674 e 3,679 minutos, respectivamente. Percebese que os valores encontrados estão bem próximos do valor padrão, o que ratifica a presença de ácido ascórbico. Com os resultados obtidos pela análise em HPLC, obteve-se uma curva analítica para quantificação do ácido ascórbico, a partir das amostras de concentração já conhecida $(0.5,1.0,1.5,3.0$ e $5.0 \mathrm{mg} / 100 \mathrm{~mL})$.

Figura 9 - Curva Analítica para Quantificação de Ácido Ascórbico.

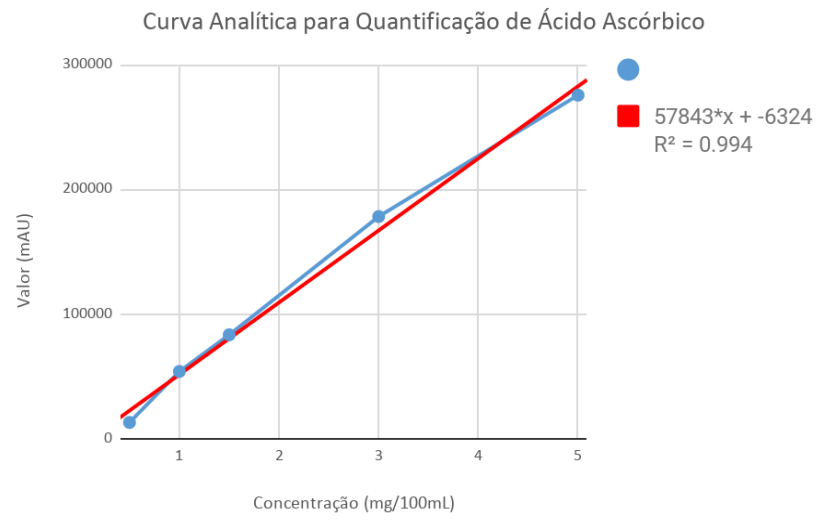

A partir da equação da reta do Figura 9 e a partir dos valores de absorbância obtidos na análise HPLC das outras amostras foi possível quantificar o teor ascórbico, como mostra a Tabela 2:

Tabela 2: Valores de ácido ascórbico presente nas amostras

\begin{tabular}{|c|c|}
\hline Amostra & Concentração $\mathbf{( m g / 1 0 0 m L )}$ \\
\hline Cerveja com Camu-Camu & 15,86 \\
\hline Cerveja sem Camu-Camu & 0 \\
\hline Cerveja Comercial & 0 \\
\hline Extrato & 422,16 \\
\hline
\end{tabular}

Pesquisou-se então dados na literatura para comparar com os valores de concentração obtidos. Utilizou-se o vinho como parâmetro por também se tratar de uma bebida resultante de fermentação alcoólica. A Tabela 3 constitui-se de dados adquiridos por Barril et al (2016), onde apresentam-se os valores de ácido ascórbico presente em diferentes vinhos.

Tabela 3: Teores de ácido ascórbico em vinhos brancos

\begin{tabular}{|c|c|}
\hline Vinho & Ácido Ascórbico $(\mathbf{m g} / \mathbf{1 0 0 m L})$ \\
\hline Semillon & $4,1-4,4$ \\
\hline Chardonnay & 0,2 \\
\hline Sauvignon Blanc & 8,5 \\
\hline
\end{tabular}

Apesar de sucos e bebidas de frutas/néctares UHT possuírem um processo mais severo de pasteurização que a cerveja, para efeito comparativo, também pesquisou-se sobre os 


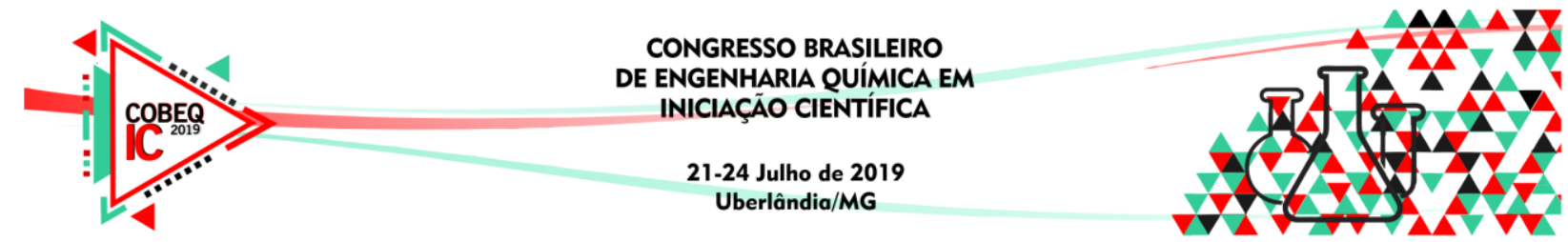

valores de vitamina $\mathrm{C}$ em sucos industrializados de uma certa marca, cujo os dados estavam disponíveis no site da empresa fornecedora. Com base nesses dados apresentados pela Del Valle Produtos (2018), montou-se a Tabela 4.

Tabela 4: Teores de Vitamina $\mathrm{C}$ em sucos industrializados

\begin{tabular}{|c|c|}
\hline Suco Industrializado & Teor de Vitamina C (mg/100mL) \\
\hline Laranja & 7 \\
\hline Uva & 3,35 \\
\hline Maçã & 12,5 \\
\hline
\end{tabular}

Observa-se que os valores contidos na Tabela 3 e 4 são inferiores ao valor encontrado na cerveja produzida com o fruto de camu-camu como adjunto. Portanto, em relação à vitamina $\mathrm{C}$, a cerveja possui maior teor de propriedades nutracêuticas que certos vinhos e sucos industrializados.

\section{CONCLUSÃO}

Analisando os resultados obtidos, nota-se que o objetivo do estudo foi alcançado pois, conforme previsto na literatura, o camu-camu apresentou alta concentração de ácido ascórbico e com isso, produziu-se uma cerveja com valores promissores de vitamina C. Como dito anteriormente, os valores mínimos diários recomendados de vitamina $\mathrm{C}$ são de $90 \mathrm{mg}$ para homens e $75 \mathrm{mg}$ para mulheres. Portanto, a cerveja produzida mostrou potencial para suprir esta necessidade e conceber benefícios à saúde.

\section{REFERÊNCIAS BIBLIOGRÁFICAS}

BARRIL, C.; RUTLEDGE, D.N.; SCOLLARY, G.R.; CLARK, A.C. Ascorbic acid and White wine production: a review of beneficial versus detrimental impacts. Australian jornal of Grope and Wine Research: 2016.

BEER JUDGE CERTIFICATION PROGRAM (BJCP). Disponível em: < http://www. bjcp.org/ > Acesso em: 26 de agosto de 2018.

Del Valle Produtos. Disponível em: $<$ http://www.delvalle.com.br/pt/produtos/del-vallenutri/>. Acesso em 26 de agosto de 2018.

MORADO, R. Larousse da Cerveja. Edição Brasileira, Larousse. 2009.

ROSA, J. S. et al. Desenvolvimento de um método de análise de vitamina $\mathbf{C}$ em alimentos por cromatografia líquida de alta eficiência e exclusão iônica. Ciência e Tecnologia de Alimentos. São Paulo, Campinas: 2007.

SAKAMAKA, L. S. et al. Desenvolvimento de Cerveja Artesanal de Trigo adicionada de Gengibre (Zingiber officinale Roscoe). Tópicos em ciência e tecnologia de alimentos: resultados de pesquisas acadêmicas - Volume 2: 2016.

ZAMUDIO, L.H.B. Caracterização de Vitamina C em frutos de camu-camu Myrciaria dubia (H.B.K.) em diferentes estágios de maturação do Banco Ativo de Germoplasma de Embrapa. Universidade de Brasília. Distrito Federal, Brasília: 2007. 